\title{
Compare and Contrast the Two Approaches: The 'Conventional Approach' and the 'Computational Approach' Described by Stiny and Mitchell 1978, for Analyzing an Architectural Style
}

\author{
Nujaba Binte Kabir \\ Department of Architecture, The Ahsanullah University of Science \& Technology, Dhaka, Bangladesh \\ Email: nujabakabir@gmail.com
}

\section{ARTICLE INFORMATION}

Received: April 09, 2019

Revised: May 20, 2019

Accepted: June 6, 2019

Published online: July 11, 2019

Keywords:

Architectural historians, Computational

analysis, Conventional analysis

\begin{abstract}
Architectural historians have focused more on traditional analysis of a style on the basis of concept, compositional order, construction method, structural system and much more. This approach can be called as 'Conventional approach'. On the other hand the 'Computational approach', which was described by George Stiny and William J. Mitchell in 1978, can regenerate new design of a particular style by analyzing the characteristics of that style. The question is how these two approaches conflict with each other and how they can be compared with each other. The aim of this paper is to find out the differences and comparisons between these two approaches with explanation of some examples.
\end{abstract}

DOI: http://doi.org/10.15415/cs.2019.71003

\section{Introduction}

This paper will focus on two approaches which are used to analyze an architectural style. The conventional approach and the computational analysis approach which was described by Stiny and Mitchell (1978, p17). The buildings of similar expressions and architectural characteristics are called to be a part of certain architectural style. The corpuses of buildings of certain style are perceived to be same character. Stiny and Mitchell (1978) proposed three criteria to evaluate the theory to understand a style. If simplified those criteria, they can be stated as follow:

1. It should give a new example in the style.

2. It should have the criteria to test whether a new example belongs to the original style or not.

3. It should give the explanation of the basic compositional features to design a new example of a style.

In shortly the two approaches conflict in the terms of first and third criteria and has similarity in second criteria. This will be explained in the later part of the paper. Conventionally the architectural historians analyze a style basis on it's compositional order, which represents, how a designer articulate the facade of their building, what is the grammar of each designer and how they start their design, what is the solid void relationship in the plan, elevation, what is the concept of a designer to design a space. How they play with light, what are the new elements of one's design, and what is one's construction method to develop their design. But such analysis does not give us anything new of any styles and it means this approach only describes the examples those already exists in that style.

In the computational analysis approach, there is a method which is called Shape grammar. This grammar can produce a structure by analyzing some examples (corpus) of any style from which new designs can be constructed of that style. They must satisfy functionally and structurally the original designs. How they will be the new member of the original corpus and how they can be evaluated by the three criteria is described by Stiny and Mitchell (1978). But the question is how these two approaches contrast with each other or what are the comparisons between them?

The aim of this paper is to find out the above question's answer with the example of Mughal gardens. Firstly Mughal gardens will be described on the basis how these gardens have been traditionally analyzed by the architectural historian from the century to century. After that in 1980 how Stiny and Mitchell had developed the grammar of Mughal garden (paradise) with the help of shape grammar. Stiny's grammar 
of paradise can generate new Mughal garden which belongs to the original corpus of the garden. These two approaches will be compared in terms of Mughal garden and also try to find out the difference between these two approaches.

\section{Characteristics of Conventional Approach and Computational Approach:}

\subsection{The conventional approach}

Architectural historians have been interested more on traditional analysis of a style than in finding generation of a style. They have been focused their analysis basis on following characteristics

- concept of a designer

- basic compositional order

- composition of space

- solid void relation in the space

- $\quad$ articulation of façade treatments

- use of material

- construction method

- the focal point of the design, and much more.

But this approach has no methodology to analyze a design in detail and does not show how a form can be constructed. H. Koningand \& J Eizenberg (1981, p295) had mentioned that the architectural historians generally focused on the influential and technological characteristics of building construction rather than reveling and clarifying the compositional structure of designs. On the other hand the other approach has a potentiality to analyze a style in details and can generate new examples of that style. This is the basic difference between these two approaches.

\subsection{The computational approach}

Two criteria are required to analyze a style with this approach.

- a shape grammar method

- a corpus of a style.

When an analyzer wants to analyze a style with this approach he needs several example of that style. After that a basic element can be derived which can be used as an initial shape for shape grammar method. With shape grammar method new form can generate of a style. And this new form must satisfy functionally and structurally the original designs. After that this can be evaluated by the three criteria which are described by George Stiny and William J. Mitchell in 1978.(page-1)

Here are some examples which have been analyzed both traditionally and computationally. In these examples the historians have focused the characteristics of conventional approach very clearly. And also those examples have been analyzed with other approach with the help of shape grammar.

The examples:

Frank Lloyd Wright's Prairie houses(Koning and Eizenberg 1981), the traditional Turkish houses (Cagdas 1996), Siza's houses (Duarte 2005), Queen Anne houses(Flemming 1987), Palladian villas(Stinyand Mitchell 1978), Bungalows of Buffalo (Downing and Flemming 1981), Taiwanese Vernacular houses (Chiou and Krishnamurtu 1995), Vernacular Hayat houses (Colakoglu 2005), Modern apartment houses of Seoul (Seo 2007), the Windows of Frank Lloyd Wright (Rollo 1994), the Mughal Gardens (Stinyand Mitchell 1980) and much more. Among Wright's Prairie houses and Queen Anne houses and Mughal gardens are going to be described.

\section{Frank Lloyd Wright's Prairie houses:}

Traditionally Prairie style's houses have been analyzed by the historian (Massey1996), (Quinan2004) according to their balance, the influence of Beaux Arts and Japanese traditional houses and the organic qualities of Japanese houses and use of horizontal eves. In these houses fireplace is the focal of the design. But with this analysis there is nothing new in his style which is predictive. And also there is no other methodology for evaluating these designs in detail. $\mathrm{H}$ Koning and $\mathrm{J}$ Eizenberg had analyzed these prairie houses by applying shape grammar method in 1981. They mentioned in their paper that, in prairie style houses there are some spatial relationship between the three dimensional building blocks and this spatial relationships is the primary consideration to create a language of prairie style houses with the help of the parametric shape grammar (Koning and Eizenberg 1981). For shape grammar analysis they took a corpus of eleven houses of Wright's prairie style houses. In this style fireplace which is a focus of the prairie style houses and the other rooms are placed around the fireplace. All rooms radiate around the fireplace. And this simple concept was used to develop the shape rules. They had developed 99 rules to generate three new prairie style's houses among the Wright's prairie style houses.

\subsection{Difference and comparison between conventional and computational approach of Prairie style's houses}

The differences between these two approaches are, traditionally architectural historians had described Prairie style's houses theoretically but there is no visual methodology which can analyze these designs in details. With other approach it is possible to analyze these designs in details and after that to generate new designs of that style. 
If the results of these two approaches are compared it can be found that, the computational analysis can generate a new design of prairie style which has the similar characteristics of that style. And these characteristics have been also described by conventional analysis.

\section{Queen Anne houses}

According to Flemming (1986), the styles of the houses are very contrasting in their shapes, textures and colors. The ground plan is irregular, different elevation was used in each façade, the roof has intersecting ridges and turrets, using of different materials, there are porches, overhangs, bay windows, oriels, balconies, leaded glass, stained glass, clustered brick chimneys and much more. These all types of features created a design with unity. The main feature of the house is the entrance hall which is located in the center and main stairs located at the 90 degree position to each other. This type of analysis only

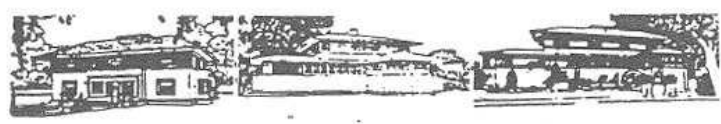

(a)

(b)
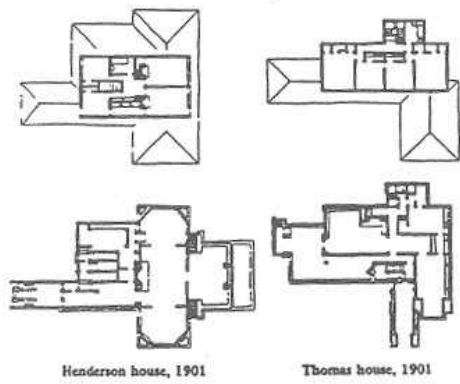

(c)

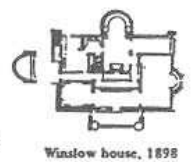

described the features separately. There should be some approach which can identify and relate these features to each other. To focus on this reason U Flemming(1986) had analyzed these Queen Anne houses by applying shape grammar method. For this purpose Flemming took nineteen plans of Queen Anne houses and clustered them into four types. He had divided the analysis process into two phases;

- the first phase is to analyze its basic layout

- the second phase articulate the plan generated from the first phase in a particular style.

To generate the basic layout Flemming used 'Hall' as an initial shape and developed 15 rules. For 3 dimensional extrusions he developed 2 rules and for exterior articulation he again developed 32 rules. After the using all rules he was able to generate a basic house of Queen Anne style which demonstrate every single characteristics of the Queen Anne style and explain its overall geometry.

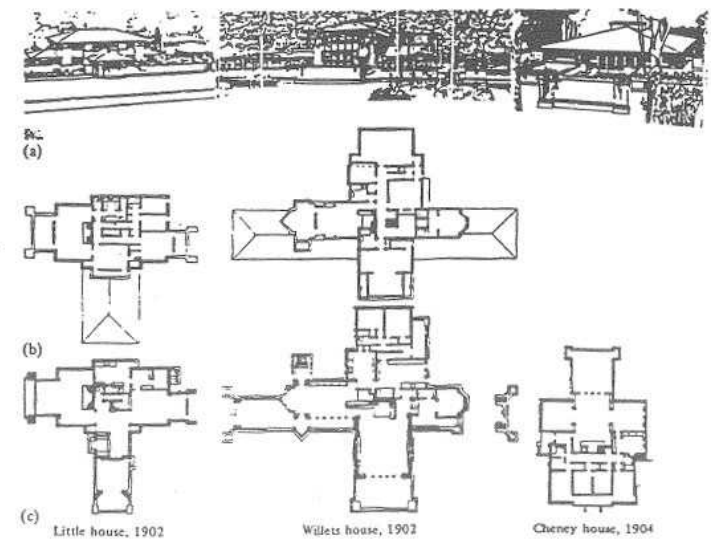

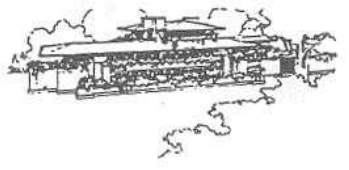

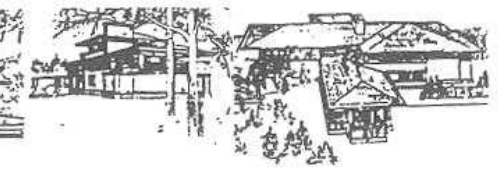

(a)

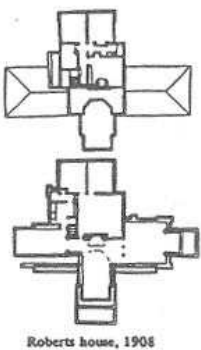

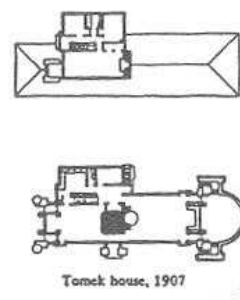

Roberts houme, 1906$$
\text { Roberts bo }
$$

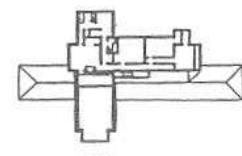

(b)
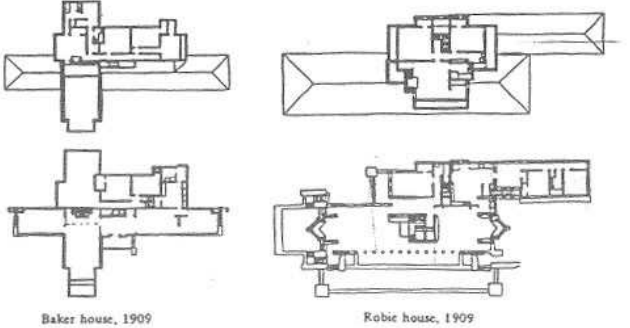

(b)

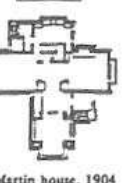

Figure 1. The corpus of Prairie style's houses (Source: Koning \& Eizenberg1981) 


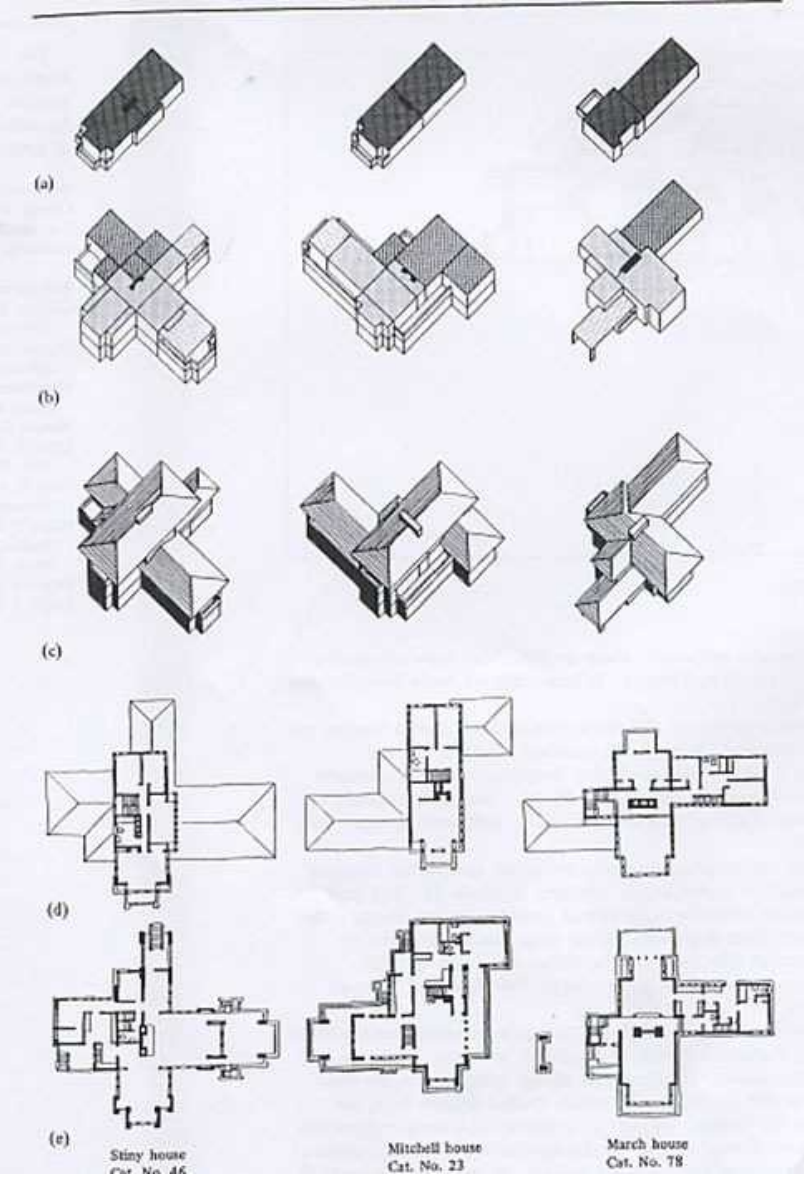

Figure 2. Three new Prairie style houses generated after shape grammar analysis. (Source: Koning \& Eizenberg 1981)

\subsection{Difference and comparison between conventional and computational approach of Queen Anne houses}

Conventionally Queen Anne houses have been analyzed in terms of their design elements or features. But this type of analysis only described the features separately. There should be some approach which can identify and relate these features to each other. Computational analysis is the approach which can generate a basic house of Queen Anne style and this basic house demonstrates every part and features of the house and relates to each other and explains its overall geometry. It means that first approach only deals with those lists which belongs to the styles that means the corpus but on the other hand second one generate a new example which do not exists before in the style.

In this example if the two approaches are compared, it can be found that both approaches need the basic characteristics to analyze a style. Here computational analysis generate a basic house of Queen Anne houses style and all the features of this style can be further applied
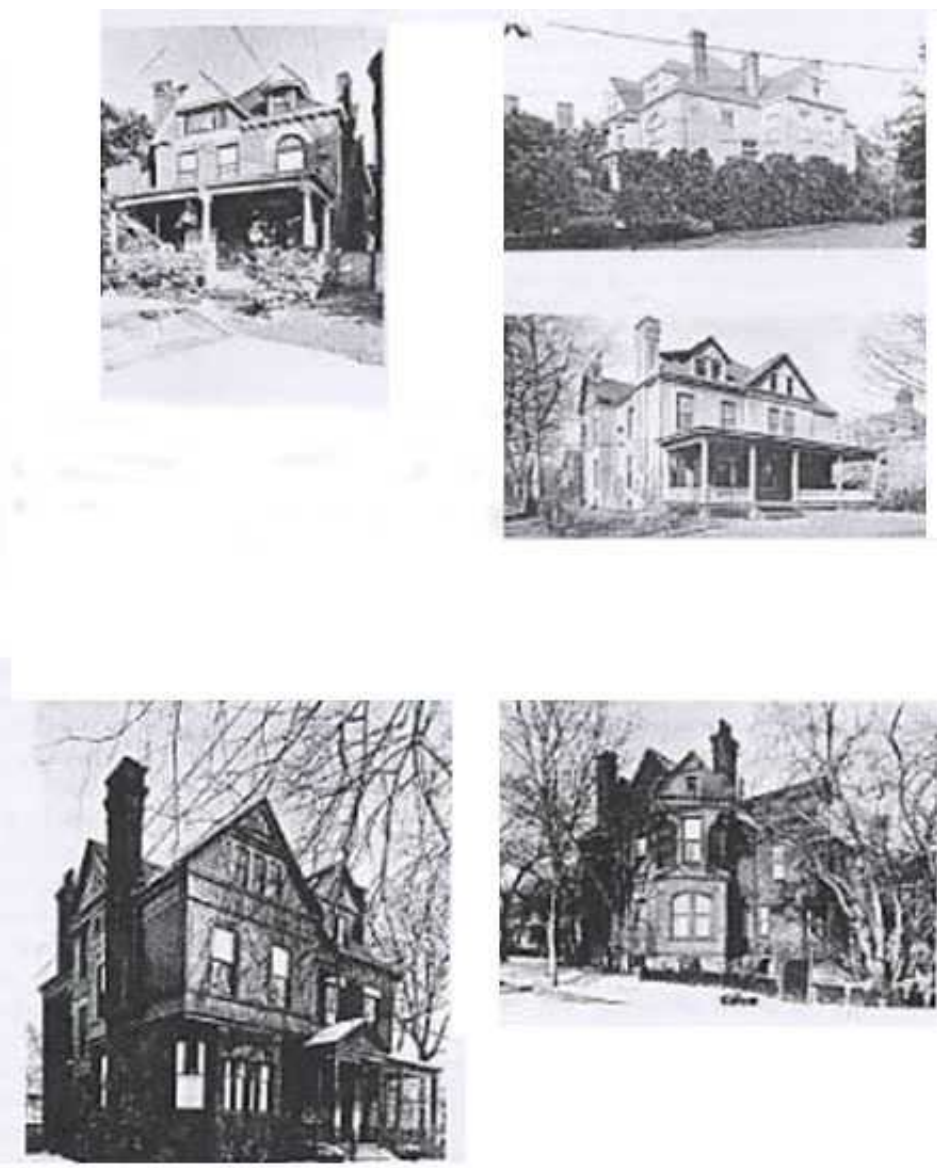

Figure 3. The Queen Anne houses (Source: Flemming,1987)

on this basic houses. Architectural historian had also traditionally analyzed those features. So it can be said that the new design belongs to the original corpus of the Queen Anne houses.

\section{The Mughal Garden}

Babur, the first emperor of Mughal had introduced the Timurid form of the Char-bagh. A Char-bagh is the Persian walled garden divided into four quadrants by two intersecting walkways and canals. For plantation in the garden a pool was provided at the intersection point of two canals. This intersecting cross also represent religious diagram. But for the Mughal Garden's design it represents the four rivers that flows from the Paradise (Book of Genesis). Babur had established a garden which is unequal on the bank of river Jamnain Agra, India. This garden was the first example in India with four walkways. After that Babur and his followers had established many gardens in Lahore, Pakistan and Kashmir, Delhi, Agra in India. Among all of those gardens 


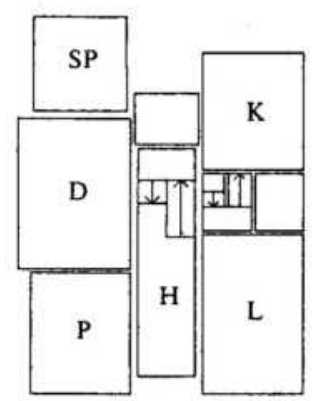

Plan Cl

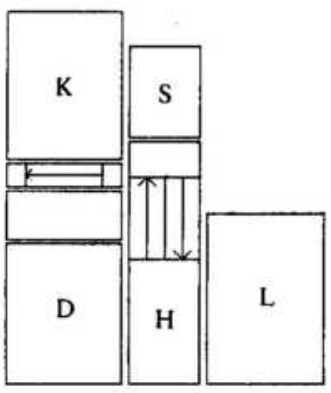

Plan C4

(c)

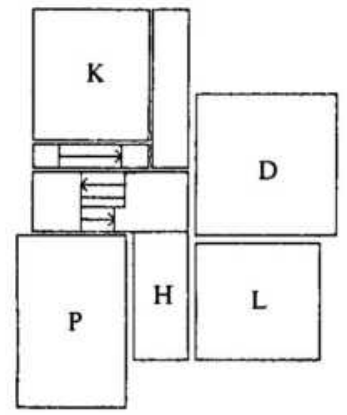

Plan D1

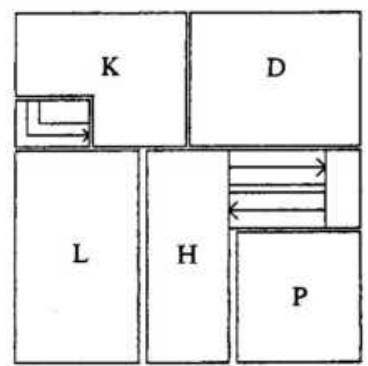

Plan D4

(d)

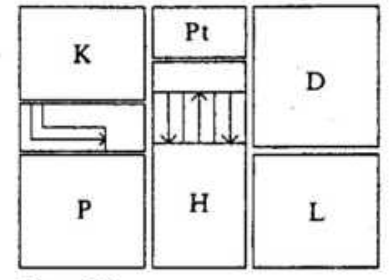

Plan C2

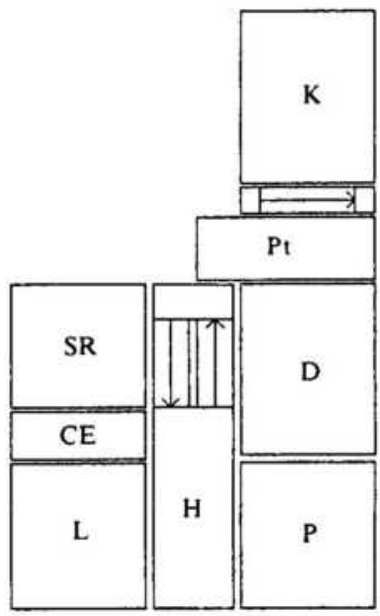

Plan C5

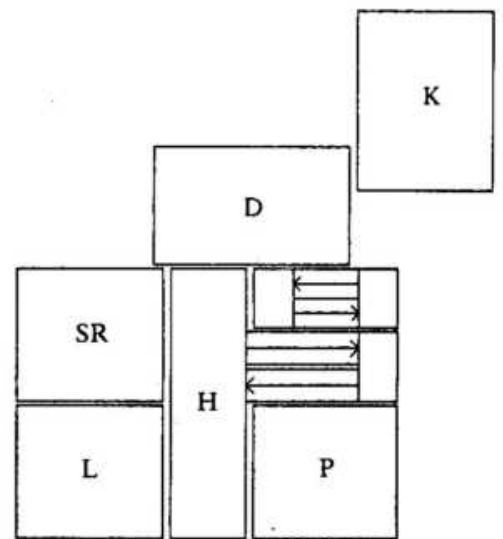

Plan D2

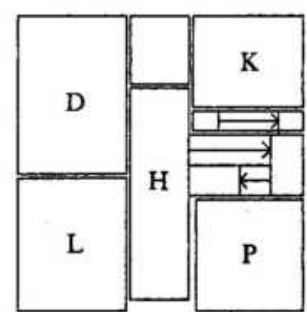

Plan D5

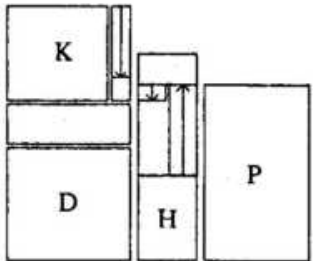

Plan C3

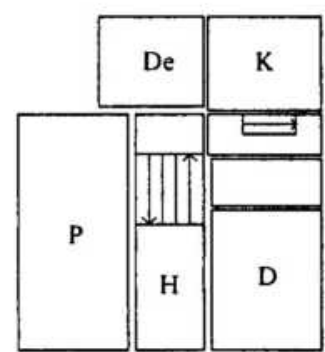

Plan $\mathrm{C} 6$

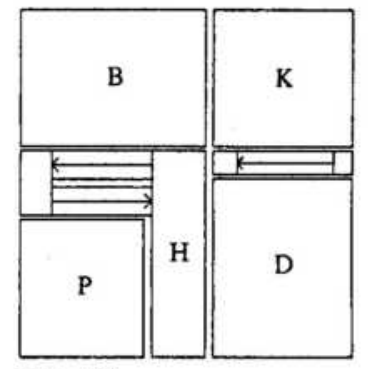

Plan D3

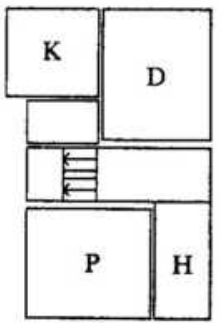

Plan D6

Figure 5. Sample of plans of Queen Anne houses (Source: Flemming, 1987) 

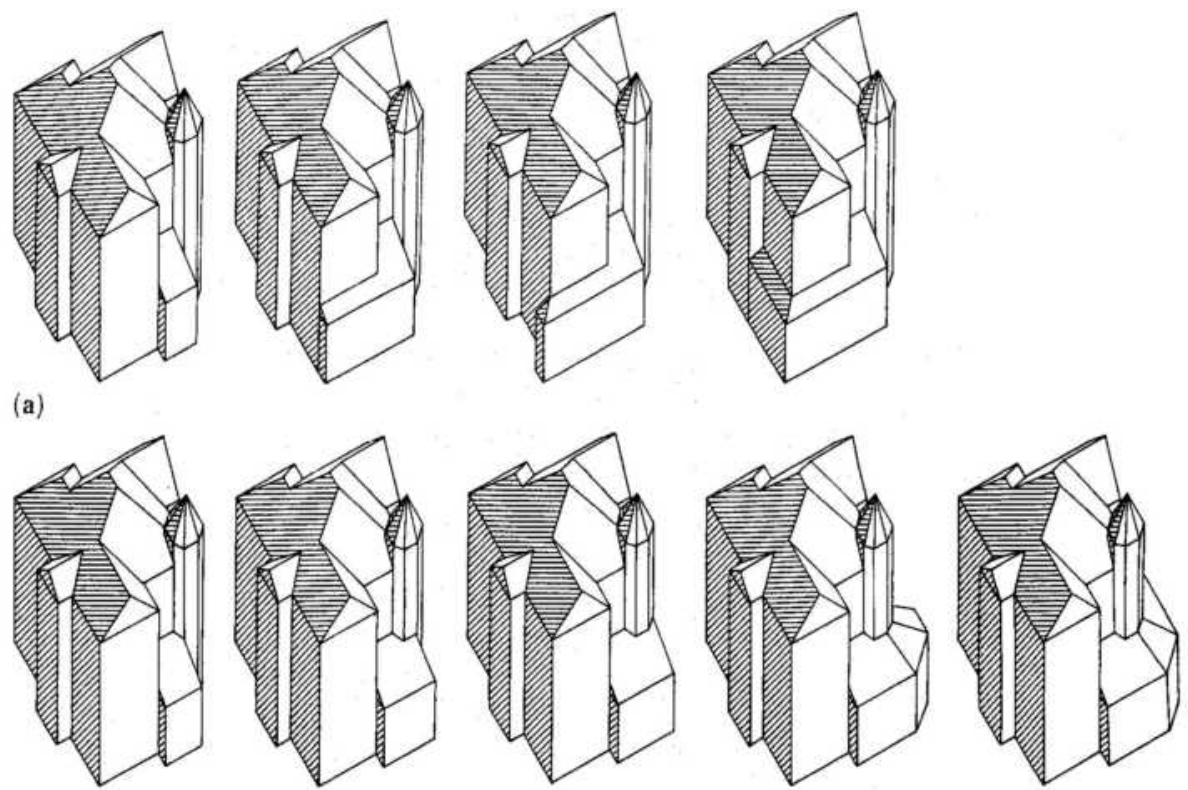

(b)

Figure 6. The basic Queen Anne houses generated after computational analysis (Source: Flemming, 1987)

the riverfront gardens at Agra are considered as well solved garden in Mughal garden design.

The main characteristics of Mughal gardens are:

- gardens have oblong plan

- two major axis represent by middle canal and a pool at the intersection point.

- the main building on a terrace set at the end of the main axis

- these two axis divide the garden into four part with raised paved walkways.

The above mentioned analysis is very traditional, which has been done by the Historian from a long time (Petruccioli 1997), (Conan1999), (Elizabeth 2000) and many more. And this type of analysis does not produce anything new and always deal with the existing examples. To generate something new from the Mughal garden's design George Stiny and W J Mitchell in 1980 took an attempt to analyze the gardens by the shape grammar methodology. After examining the sets of Char-bagh's design they had decided to represent the design by parametric shape grammar. With the help of the grammar it was possible to produce a language of Char bagh's ground floor plans in detail. (Stiny and Mitchell, 1980). For computational analysis, a set of examples or corpus is needed to develop a grammar. Stiny and Mitchell stated that to understand certain architectural style, it requires some important fundamental characteristics of the examples of the corpus. With the help of these characteristics one can provide rules to generate new examples of the style. These new examples must not only satisfy the characteristics but also represent functionally and symbolically of the existing designs (Stiny and Mitchell, 1981). They had clearly mentioned that for this analysis a corpus is needed and main features of the examples which will help to produce rules for the grammar. These grammars will generate the new example of the style. For their analysis they took a corpus consist of three Mughal gardens' ground floor plans drawn by the Baroness Gothein (1926). They are:

- garden of TajMahal in Agra, India.

- Shalamar Bagh in Lahore, Pakistan.

- the Tomb of Jahangir at Shahdara near Lahore, Pakistan.

All of these gardens were built by the Mughal emperors in seventeenth century.

After selecting the corpus of 3 examples then Stiny and Mitchell was looking for the main features or motif of the style. These are:

- Site parti is a square divide into four similar squares.

- Square and octagonal motifs for canal systems.

- Inserting canal system in a site parti.

- Arrangement of borders.

When all the features were fixed, then they go for the shape grammar analysis. They choose the cross axis as initial shape and developed 39 rules to complete the ground floor plans of Char-bagh. First 14 rules generate a plan with site parti, middle canal systems and produced borders. Rule 15-21 help to generate the middle canal systems as square or octagonal shape. Rule 22-39 help to produce the final plan of Char-bagh. 

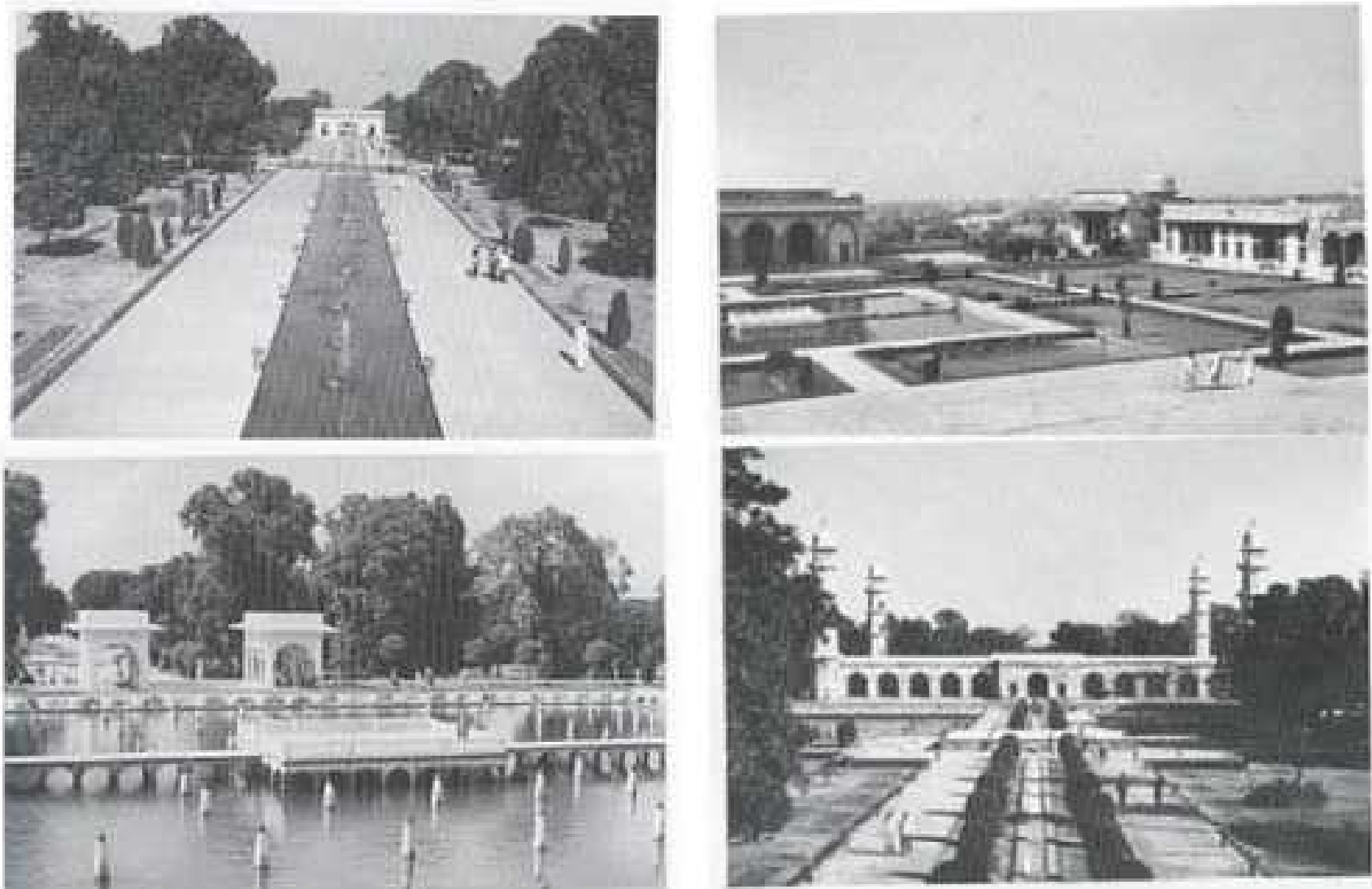

Figure 7. The garden view of Shalamar and Jahangri's tomb in Lahore (Source: Stiny \& Mitchell, 1980).

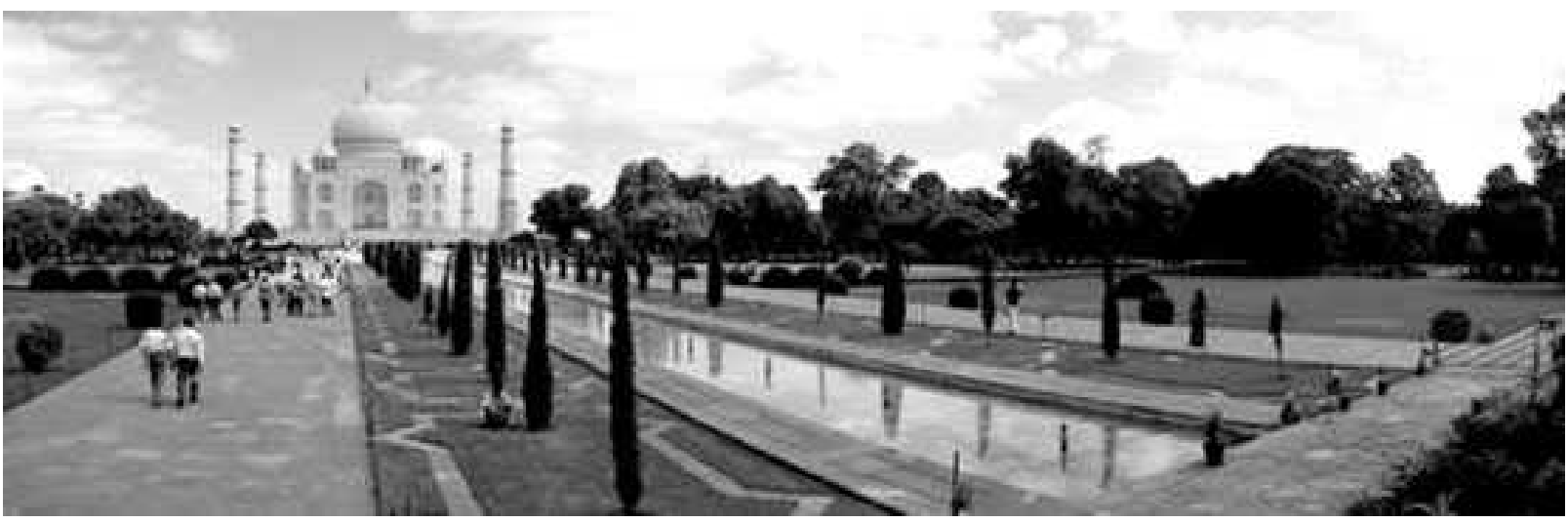

Figure 8. The garden view of Taj Mahal in Agra

\subsection{Difference and comparison between conventional and computational approach of Mughal gardens}

From above explanation of Char-bagh now the two approaches can be compared.

Traditionally Char-bagh was analyzed according to its middle canal, an octagonal or a square shape central water reservoir, arrangement of borders, walkways and much more. For computational approach Stiny and Mitchell took these characteristics as the basic elements of their analysis. Basically these two tasks can be compared according to the characteristics of a style. Actually both approaches need the characteristics of any style to analyze them. And this is the main similarity between them. 

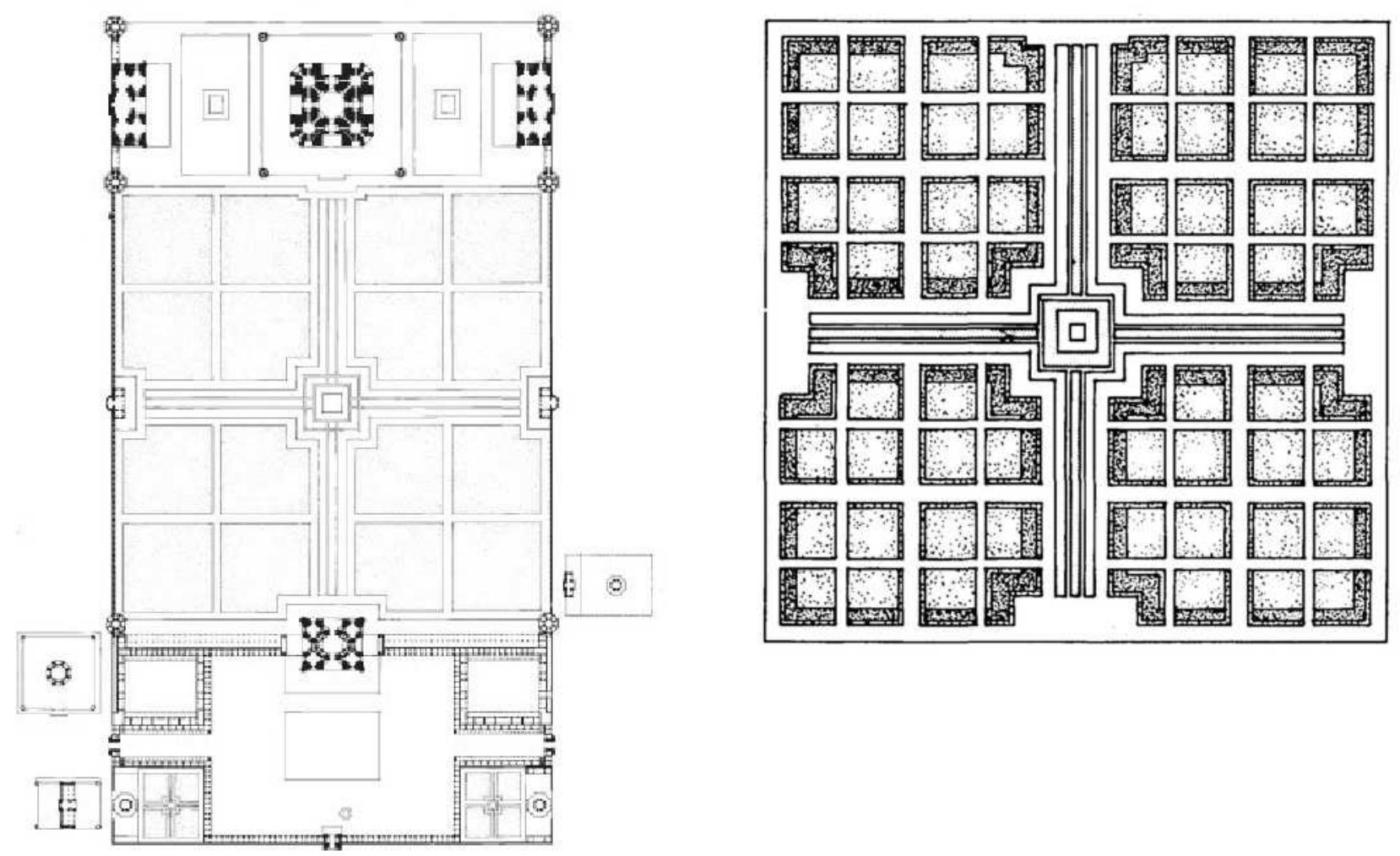

Figure 9. The ground plan of Taj Mahal in Agra, and the ground plan of Taj garden (Source: Stiny \& Mitchell, 1980)
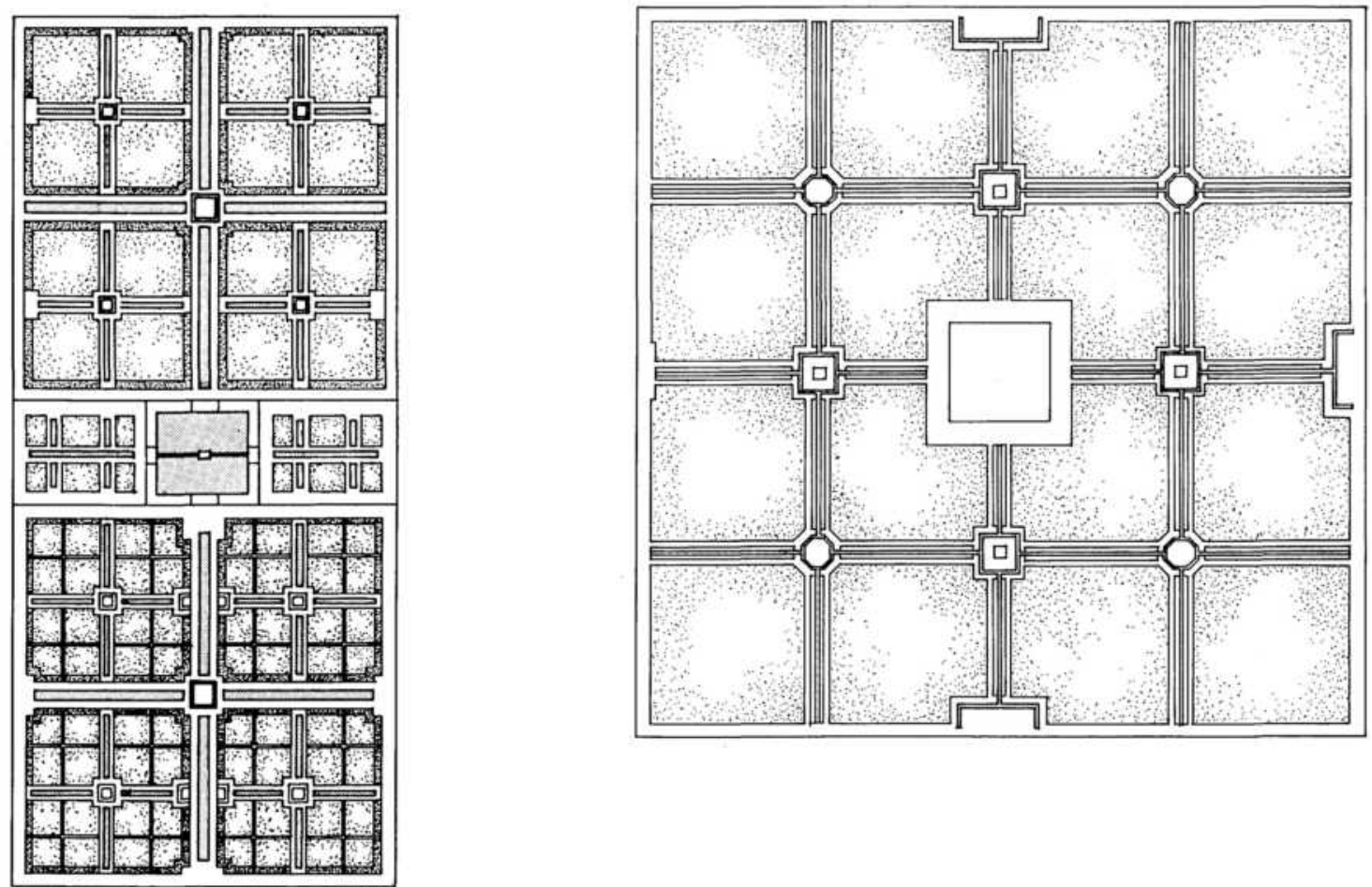

Figure 10. The ground floor plan of Shalamar garden, and Tomb of Jahangir in Lahore. (Source: Stiny \& Mitchell, 1980. 

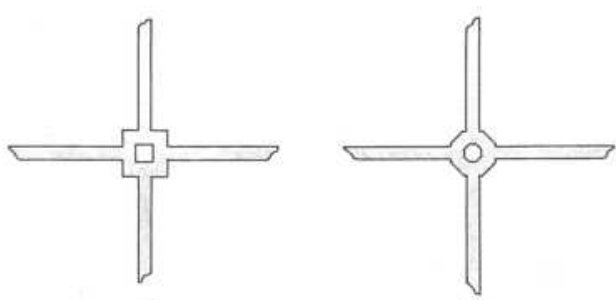

(a)

Square and octagonal motifs for canal systems.
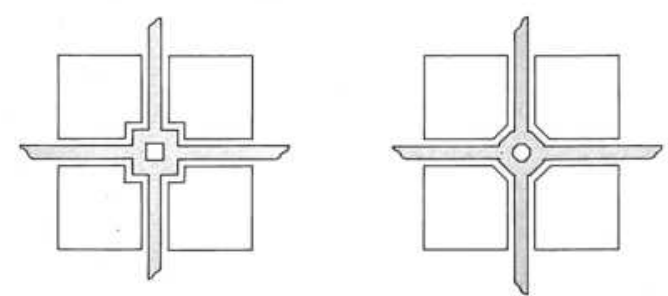

Inserting canal systems in a site parti

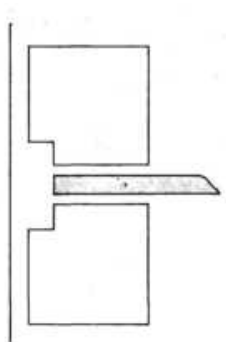

(a)
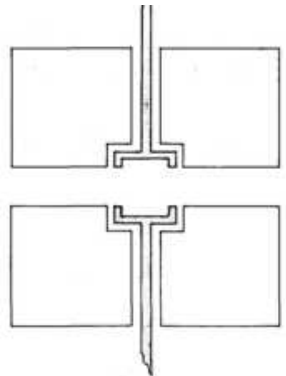

(b)

Motifs for ornamenting the ends of canals.

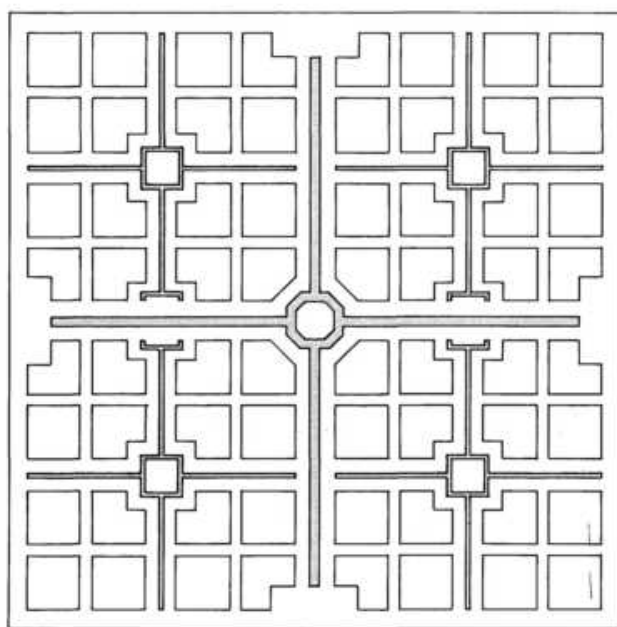

A possible arrangement of canal systems in a site parti.
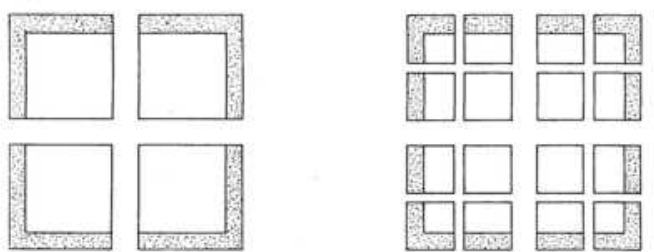

Examples of borders that frame central pairs of orthogonal arteries.
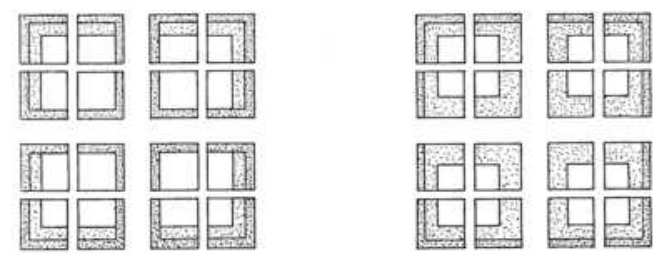

(a)

Case 1

(b)

Case 2

The interaction of multiple borders of different widths.

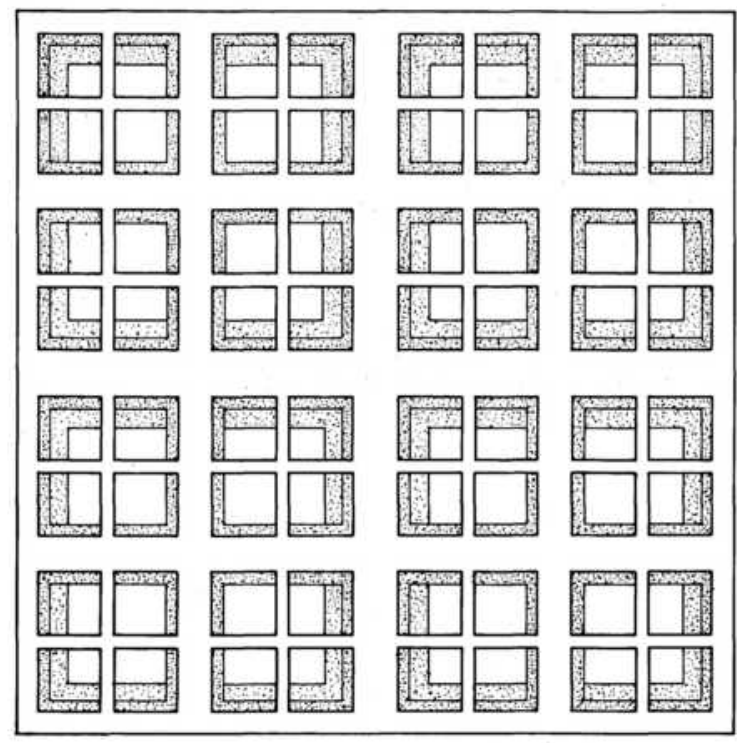

A possible arrangement of borders in a site parti.

Figure 11. Motifs for middle canal and border (Source: Stiny \& Mitchell, 1980) 

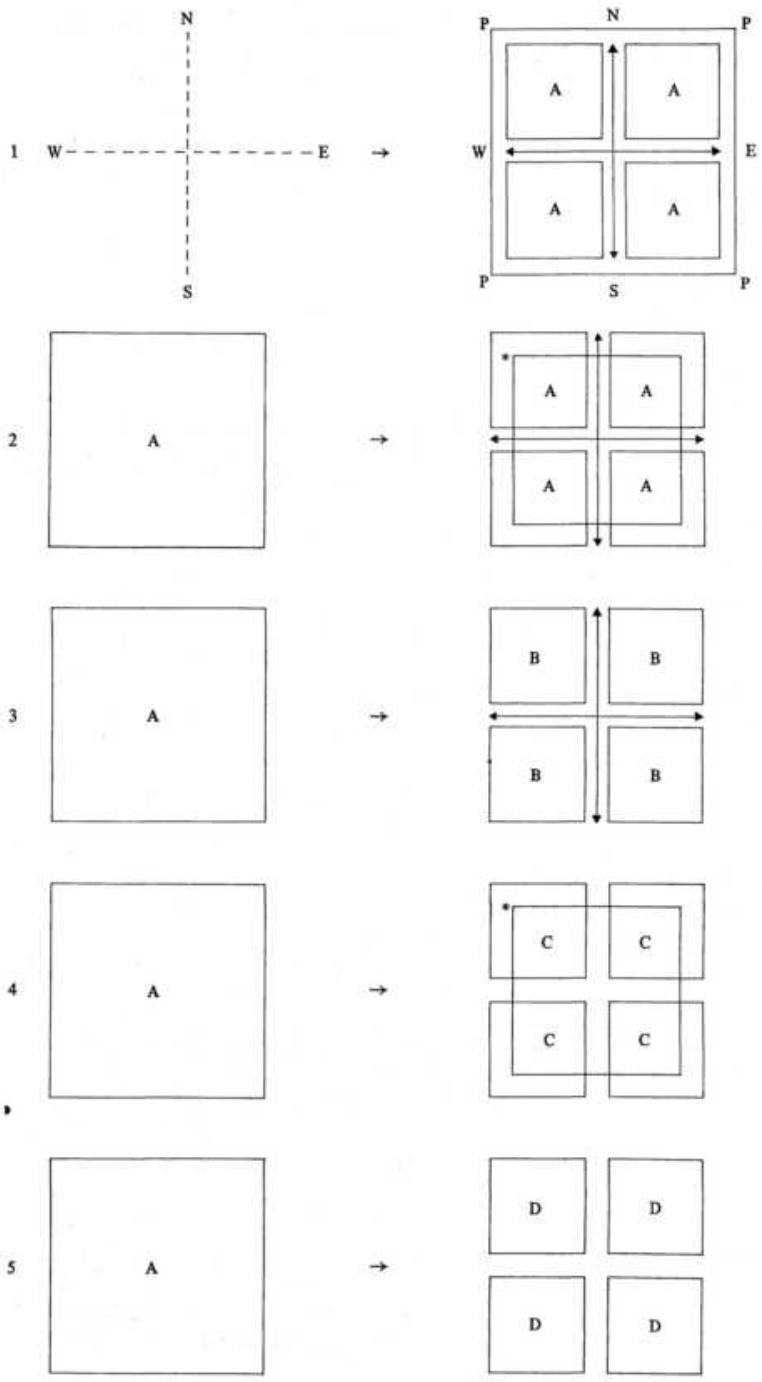

Shape rule schemata applied in stage 1 of the char-bagh generation process.
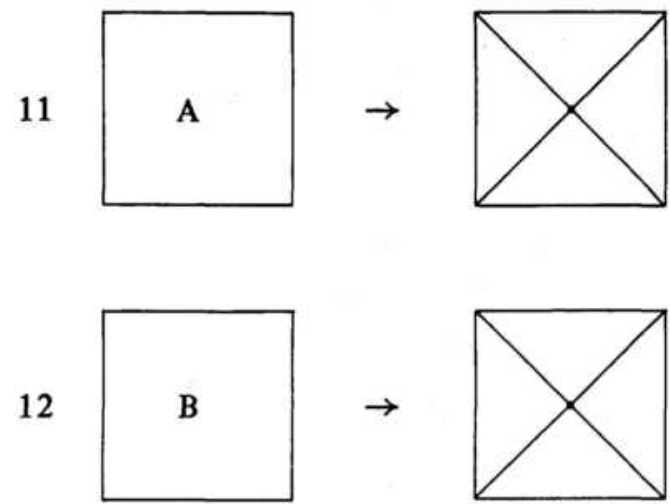
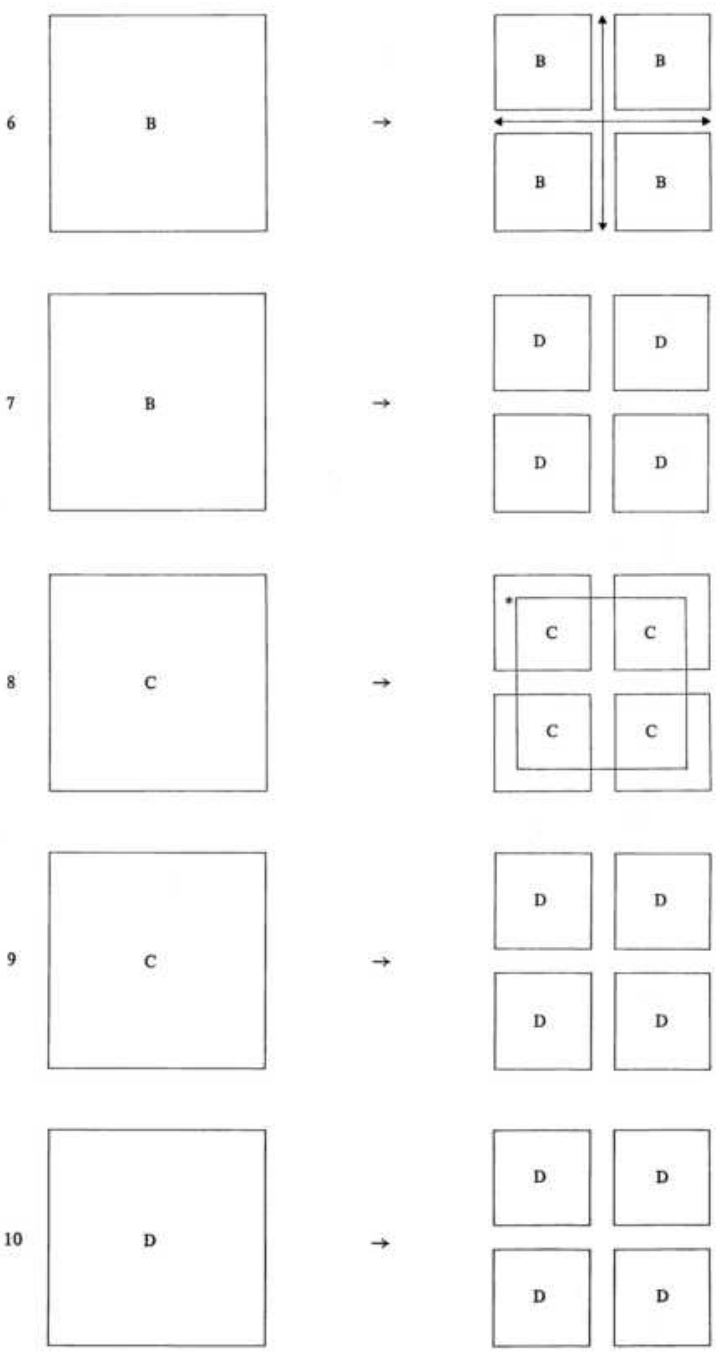

(continued)

13
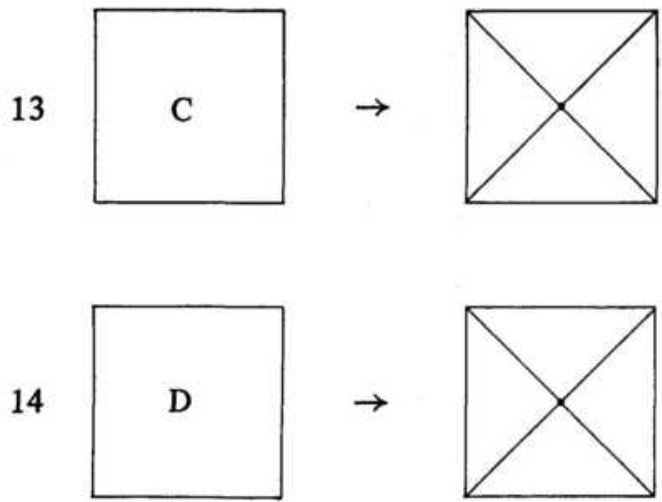

Figure12. Rules 1-14 (Source: Stiny \& Mitchell, 1980) 

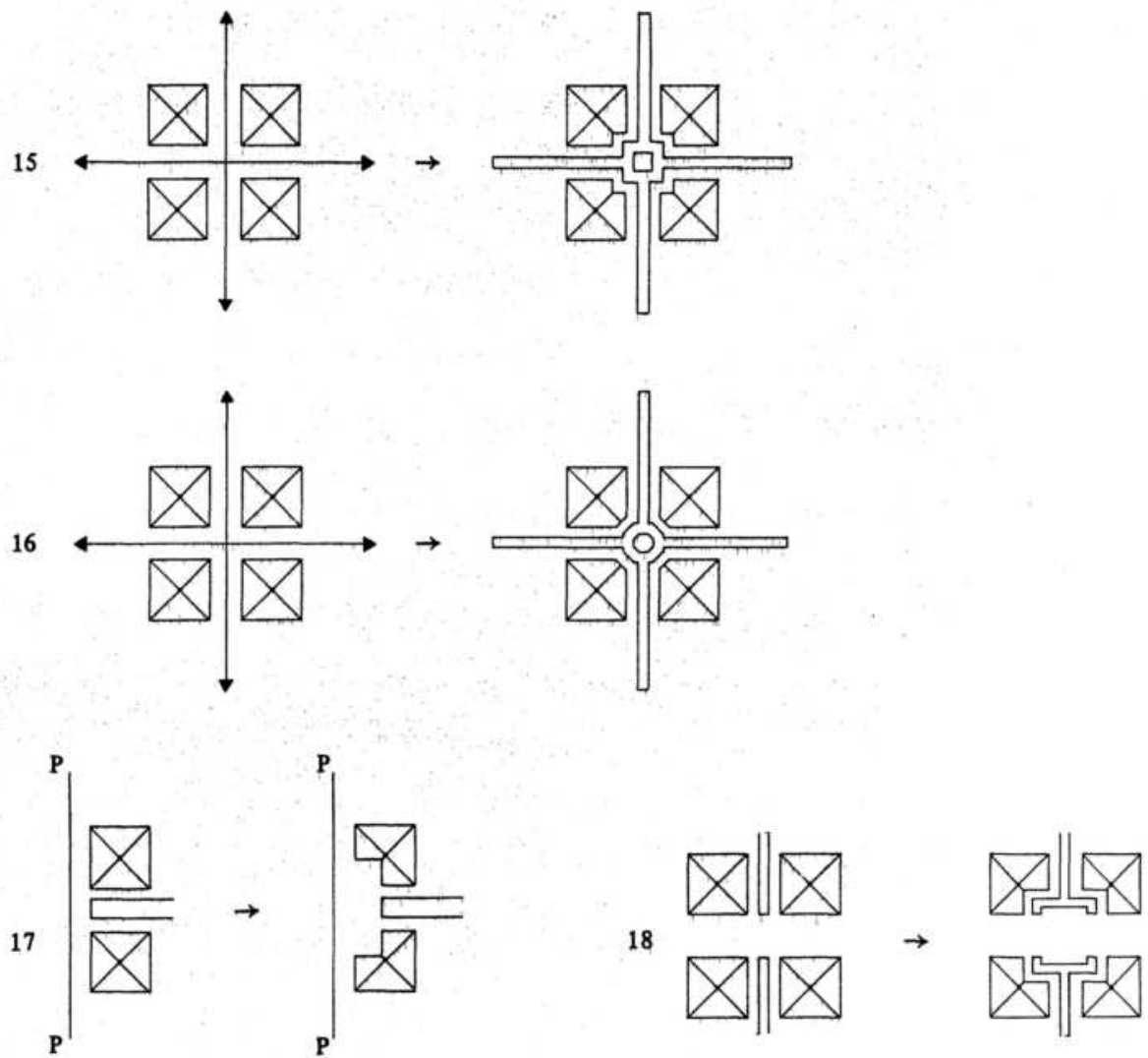

Shape rule schemata applied to insert canal systems in stage 2 of the char-bagh generation process.

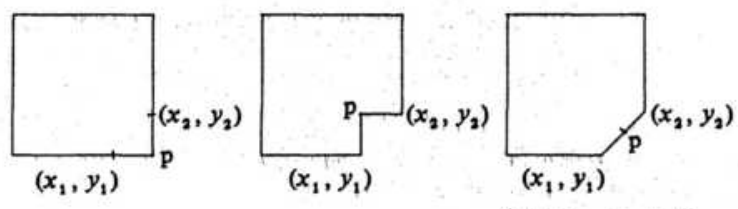

$\mathrm{p}=\left(x_{2}, y_{1}\right) \quad \mathrm{p}=\left(x_{1}, y_{2}\right) \quad \mathrm{p}=\left(\frac{x_{1}+x_{2}}{2}, \frac{y_{1}+y_{2}}{2}\right)$

Parameterizing the corners of squares to allow for inflections.

19

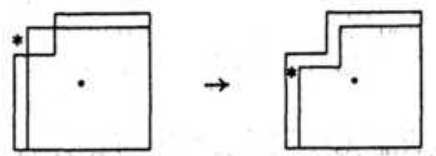

20
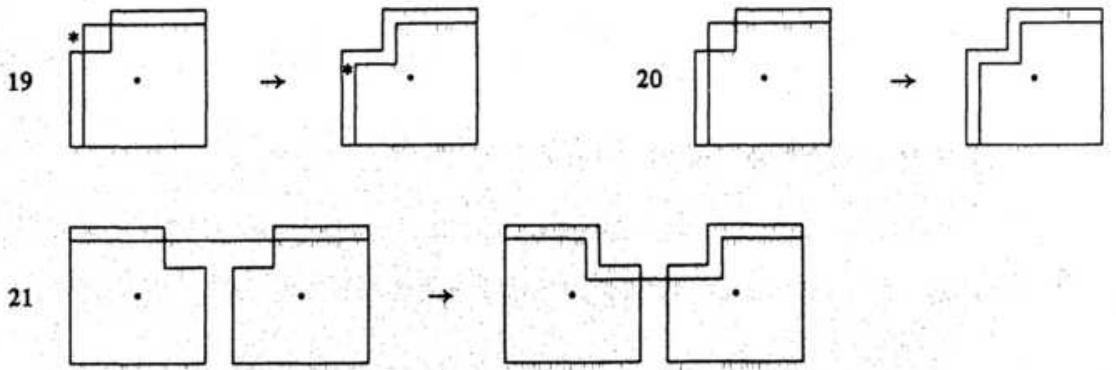

Examples of shape rule schemata used to alter borders passing through squares with inflected corners.

Figure 13. Rules 15-21 (Source: Stiny \& Mitchell, 1980) 

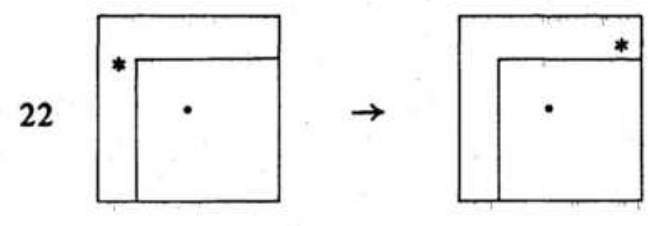

27
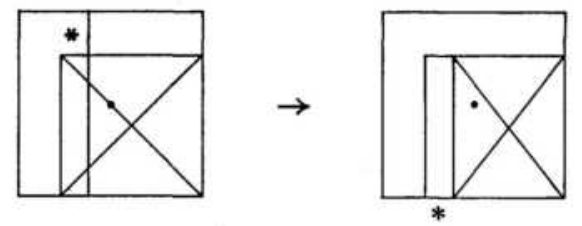

28
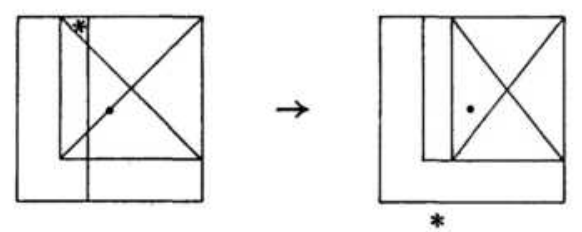

23
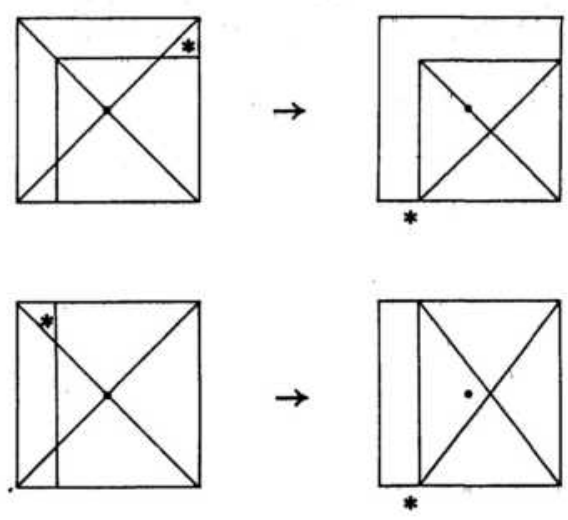

9

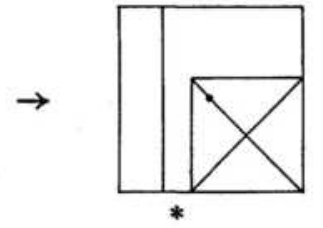

30
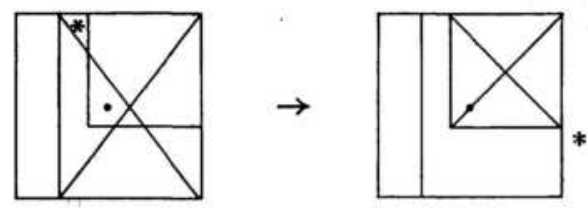

31
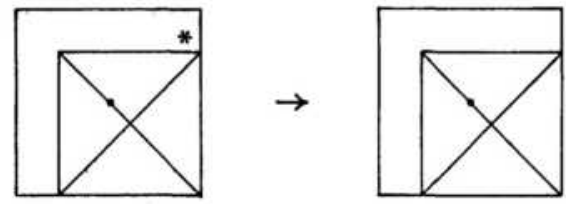

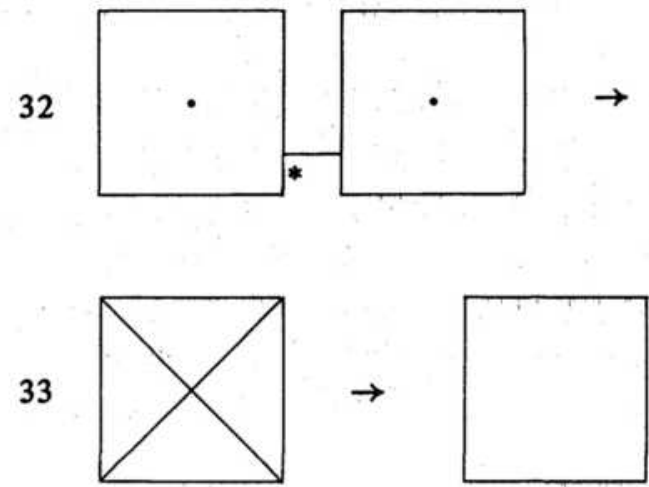

Shape rule schemata applied to determine borders in stage 3 of the char-bagh generation

process.

Figure 14. Rules 22-33 (Source: Stiny \& Mitchell, 1980) 


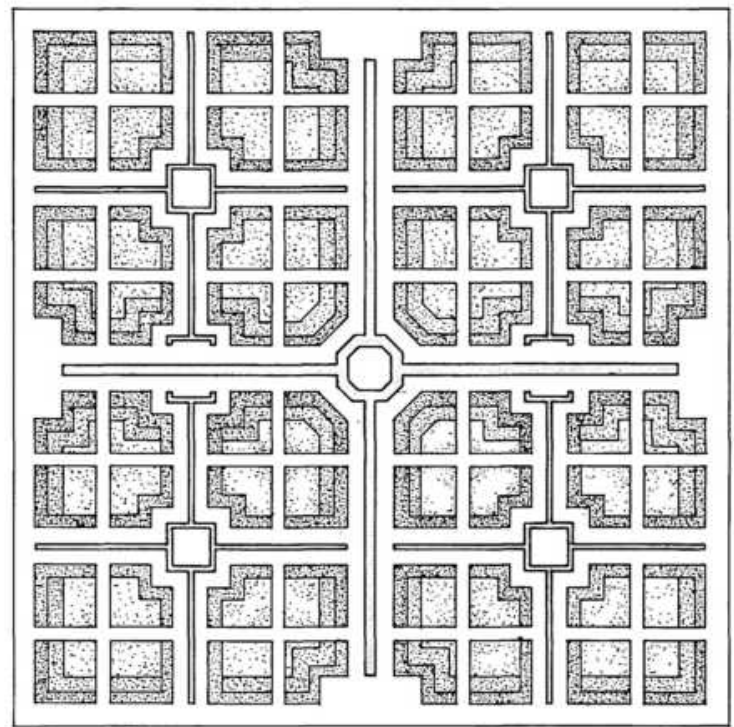

Figure 15. The complete ground plan after applying all rules (Source: Stiny \& Mitchell, 1980)
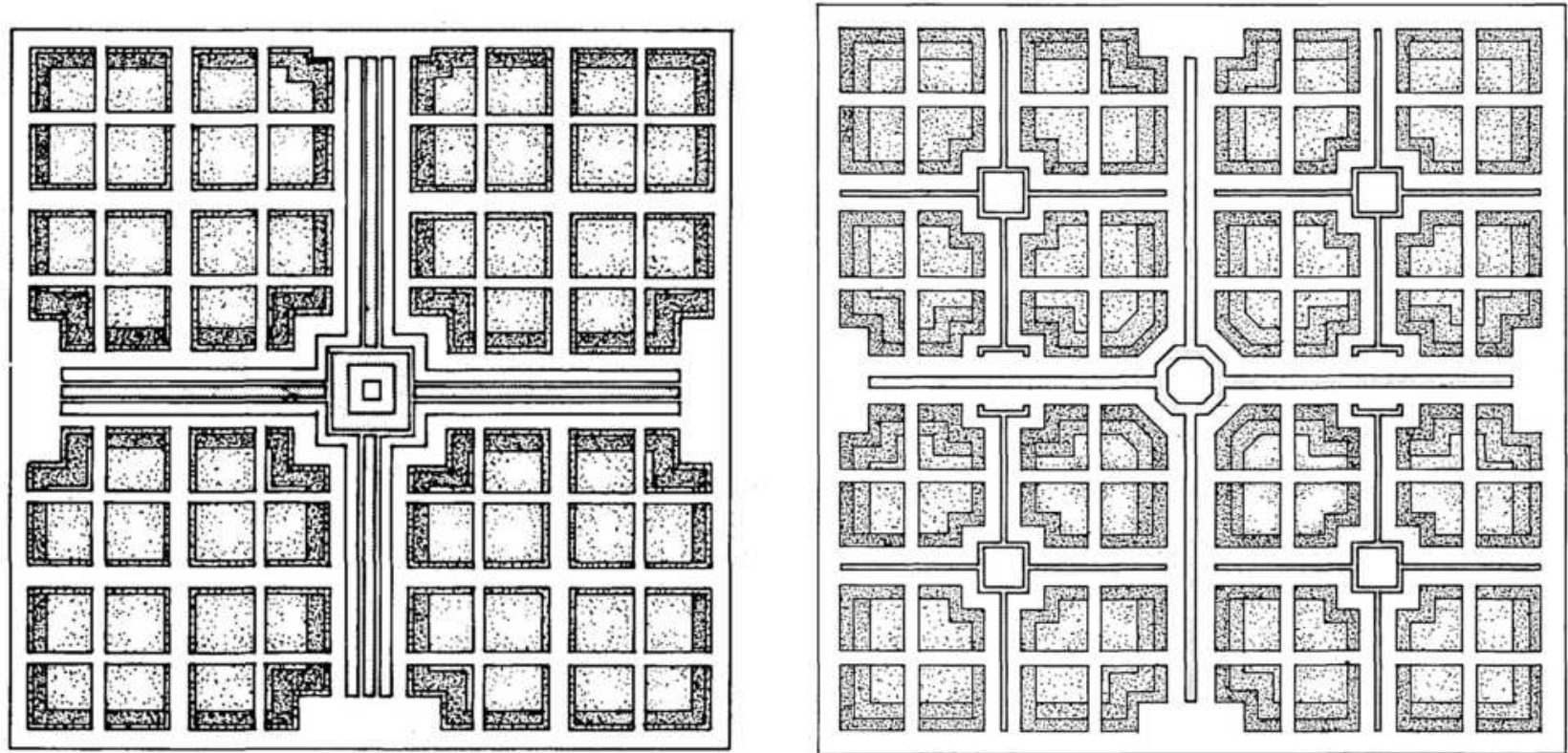

Figure 16. The two ground plans of a Char-bagh (Source: Stiny \& Mitchell, 1980)

Main differences between these two approaches are, one approach only analyzed the characteristics of the garden and on other hand other approach can produce a complete new plan of the garden with the help of these characteristics.

With the help of Stiny's grammar of paradise a tree consists of 14 new plans of Char-bagh has been generated. But the plans are not completed yet because of using only first 10 rules of the paradise grammar. More plans might be generated by applying all the rules. But the question is, are all of them belong to the same corpus of Char-bagh?
The only possible way is to compare all the plans with the characteristics of the corpus of Char-bagh. After that all those new plans ( $\mathrm{p}-1)$ might have the same characteristics as same as the original one.

\section{Conclusion}

According to the three criteria of Stiny and Mitchell (1978) for evaluating the theory to understand a style we can compare and contrast the two approaches. The criteria are: 
- It should give a new example in the style.

- It should have the criteria to test whether a new example belongs to the original style or not.

- It should give the explanation of the basic compositional features to design a new example of a style.

If the two approaches are compared, with the first one it can be seen that conventional approach only deals with the examples that already exists in the style on the other hand computational approach generates new examples which are not in the style. But for the second criteria the two approaches are also compared. For conventional approach one can pick one example from the list and analyze it according to the main features of the style and evaluate it whether it belongs to the original style or not. And for the second approach an analyzer can also evaluate the new example with the main feature of the style to do the test whether it fit in the new style or not. For the third criteria, the two approaches conflict with each other. From the above mentioned three examples it is also noticed that how these two approaches conflict with each other and how they are interrelated with each other. The main difference is that the computational approach can generate a new design of a style with the help of shape grammar. And if this new example has all the characteristics of that style then this design must be the new example of that style. But conventional approach only can describe the features of the style. For this approach one can choose only one example for analysis. But for other approach there should be more than one example of a certain style. In the example of Wright's Prairie houses, Queen Anne houses and Mughal gardens it is found that for computational approach authors choose a corpus of Prairie houses, Queen Anne houses and Mughal gardens. The two tasks have been compared according to the characteristics of a style. The main similarity of these two approaches is both need the main features of the styles to analyze them. In the example of Wright's Prairie houses, Queen Anne houses and Mughal gardens all the new examples have been found and judged by the features of the original style and these features have also been analyzed traditionally.

\section{References}

Attilio, P. (1997). Gardens in the Time of the Great Muslim Empires: Theoryand Design.
New York: Brill: Leiden.

Conan, M. (1999). Perspectives on Garden Histories. Washington, D.C : Dumbarton Oaks Research Library and Collection.

Elizabeth B. M. (2000). The Moonlight Garden : New Discoveries at the Taj Mahal. Washington, D.C: Arthur M. Sackler Gallery, Smithsonian Institution and the University of Washington Press, Seattle and London.

Flemming, U. (1987). More than the Sum of Parts: the Grammar of Queen Anne Houses. Environment and Planning B: Planning and Design, 14, 323-350.

Koch, E. (2001). Mughal Art and Imperial Ideology: Collected Essays. New Delhi: Oxford University Press.

Koning, H, and Eizenberg, J. (1981). The Language of the Prairie: Frank Lloyd Wright's Prairie Houses. Environment and Planning B: Planning and Design, 8, 295-323.

Massey, J. C. (1996). House Styles in America: the Old-house Journal Guide to the Architecture of American Homes. New York, N.Y: Penguin Studio.

Quinan, J. (2004). Frank Lloyd Wright's Martin House: Architecture as Portraiture. New York: Princeton Architectural Press.

Siry, J. (1996). Unity Temple: Frank Lloyd Wright and Architecture for Liberal Religion. New York: Cambridge University Press.

Stiny, G, and Mitchell, W. J. (1978). The Palladian Grammar, Environment and planning B: planning and design, 5, $5-18$.

Stiny, G. (1980). Introduction to Shape and Shape Grammars. Environment and planning B: planning and design, 7, 343-351.

Stiny, G. and Mitchell, W. J. (1980). The Grammar of Paradise: on the Generation of Mughal Gardens. Environment and Planning B: Planning and Design, 7, 209-226. 